\title{
Kindlin-2 interacts with $\beta$-catenin and YB-1 to enhance EGFR transcription during glioma progression
}

\author{
Yunwei Ou ${ }^{1,2,3,4,7}$, Zitong Zhao ${ }^{2}$, Weimin Zhang ${ }^{2}$, Qingnan Wu ${ }^{2}$, Chuanyue $\mathbf{W u}^{5,6}$, \\ Xuefeng Liu ${ }^{2}$, Ming Fu ${ }^{2}$, Nan $\mathrm{Ji}^{1}$, Dan Wang ${ }^{1}$, Jiaji Qiu ${ }^{1}$, Liwei Zhang ${ }^{1}$, Chunjiang $\mathrm{Yu}^{4}$, \\ Yongmei Song ${ }^{2}$, Qimin Zhan ${ }^{2}$ \\ ${ }^{1}$ Department of Neurosurgery, Beijing Tiantan Hospital, Capital Medical University, Beijing 100050, China \\ ${ }^{2}$ State Key Laboratory of Molecular Oncology, Cancer Institute and Cancer Hospital, Chinese Academy of Medical Sciences \\ and Peking Union Medical College, Beijing 100021, China \\ ${ }^{3}$ Beijing Neurosurgical Institute, Capital Medical University, Beijing 100050, China \\ ${ }^{4}$ Department of Neurosurgery, Beijing Sanbo Brain Hospital, Capital Medical University, Beijing 100093, China \\ ${ }^{5}$ Department of Pathology, University of Pittsburgh, Pittsburgh, PA 15261, USA \\ ${ }^{6}$ Department of Biology and Shenzhen Key Laboratory of Cell Microenvironment, South University of Science and Technology \\ of China, Shenzhen, 518055, China \\ ${ }^{7}$ China National Clinical Research Center for Neurological Diseases, Beijing 100050, China \\ Correspondence to: Chunjiang Yu, email: cjyu1955@sina.com \\ Yongmei Song, email: symlh2006@163.com \\ Qimin Zhan, email: zhanqimin@pumc.edu.cn
}

Keywords: EGFR, glioma, Kindlin-2, transcription

Received: April 20, $2016 \quad$ Accepted: August 11, $2016 \quad$ Published: October 04, 2016

\section{ABSTRACT}

Kindlin-2 promotes carcinogenesis through regulation of cell-cell and cell-extracellular matrix adhesion. However, the role of Kindlin-2 in glioma has not been elucidated. We investigated Kindlin-2 expression in 188 human glioma tissue samples. High Kindlin-2 expression was correlated with high pathological grade and a worse prognosis. Kindlin-2 promoted glioma cell motility and proliferation both in vitro and in vivo. Importantly, Kindlin-2 activated the EGFR pathway and increased EGFR mRNA levels. In addition to up-regulating Y-box binding protein-1 (YB-1) and $\beta$-catenin expression, Kindlin-2 formed a transcriptional complex with $Y B-1$ and $\beta$-catenin that bound to the EGFR promoter and enhanced transcription. The $\beta$-catenin/YB-1/EGFR pathway was required for Kindlin-2-mediated functions. Our data provide a better understanding of the mechanisms underlying glioma progression, and suggest that Kindlin-2 may be a biomarker and therapeutic target in glioma.

\section{INTRODUCTION}

Glioma is the most common and deadliest type of primary brain tumor [1]. Recent advances in microsurgical therapy, radiotherapy, chemotherapy, and other glioma therapeutic strategies have improved the survival rate [2-3]. Prolonged exposure to ionizing radiation is a risk factor for glioma [4]. DNA copy number alterations, chromosomal rearrangements, methylation alterations, genetic variants, and oncogenic fusions have been identified in glioma [5-7]. However, the exact molecular mechanisms responsible for glioma growth, invasion, therapeutic resistance, and genomic instability have not been elucidated [8-9].
Kindlin-2 (mitogen inducible gene-2 [mig-2]) mediates cell-cell and cell-extracellular matrix adhesion. Kindlin-2 activates integrins and participates in several physiological processes such as chondrogenesis [10-11], cardiac muscle formation [12], myogenesis [13], and embryonic development [14]. Recently, Kindlin-2 was shown to be involved in tumor progression. Additionally, Kindlin-2 overexpression was proposed to be a prognostic biomarker for patients with hepatocellular carcinoma [15]. Guo et al. demonstrated that Kindlin-2 was highly expressed in breast cancer and found that Kindlin-2 interacted with and stabilized EGFR to regulate breast cancer progression [16-17]. Overexpression 
of Kindlin-2 was also observed in non-small cell lung [18], pancreatic [19], and gastric cancer [20]. However, Kindlin-2 overexpression decreased proliferation and migration in colorectal carcinoma cells, while Kindlin-2 down-regulation promoted tumorigenicity in vitro and in vivo [21]. These may be attributed to the expression and function of Kindlin-2 varying among different types of cancers. We previously reported that Kindlin-2 attenuated cisplatin-induced apoptosis in human glioma cells in vitro through the $\mathrm{AKT} / \mathrm{JNK}$ and $\mathrm{AKT} / \mathrm{p} 38$ signaling pathways [22]. However, whether Kindlin-2 has a critical role in glioma progression is unclear.

In this study, we analyzed Kindlin-2 protein expression in 188 glioma tissue samples, and found that Kindlin-2 expression was correlated with tumor grade and prognosis. We also demonstrated that Kindlin-2 promoted glioma cell growth and motility in vitro and in vivo. Finally, we determined that Kindlin-2 formed a transcriptional complex with Y-box binding protein-1 (YB-1) and $\beta$-catenin that enhanced EGFR transcription and promoted glioma cell proliferation, migration, and invasion.

\section{RESULTS}

\section{High Kindlin-2 expression is correlated with high tumor grade and poor prognosis in glioma patients}

We evaluated Kindlin-2 expression in 188 glioma and 10 normal brain tissue samples by immunohistochemistry. Stronger immunoreactivity was observed in glioma compared to normal brain tissue (Figure 1A). Among 188 tumor tissue samples, there were $76(40.4 \%)$ with strong positive expression, 56 (29.8\%) with positive expression, and $56(29.8 \%)$ with negative expression. We then analyzed the correlation between clinicopathological parameters and Kindlin-2 expression in the 188 tissue samples. Kindlin-2 expression did not show a significant correlation with age or sex $(p=0.060$ and $p=0.634$, respectively). However, differences in Kindlin-2 expression were observed between high (III-IV) and low (I-II) pathological grades $(p<0.001)$ (Table 1). Higher Kindlin-2 expression was correlated with high pathological grade. Additionally, Kindlin-2 expression was associated with tumor location $(p<0.001)$ and clustered in the basal ganglia and thalamus (Table 2).

We next investigated the relationship between Kindlin-2 expression and patient prognosis. In the Kindlin-2 (++) group, 64.5\% (49/76) of the patients died from glioma. In the Kindlin-2 (+) group, 57.1\% (32/56) died from glioma. Finally, in the Kindlin-2 (-) group, $41.1 \%(23 / 56)$ died of glioma $(p=0.027)$. Analysis of the median follow-up time indicated that Kindlin-2 $(++)$ patients typically survived for 10.5 months, while Kindlin-2 (+) and Kindlin-2 (-) patients typically survived for 21.5 and 30 months, respectively $(p<0.001)$
(Table 3). Kaplan-Meier analysis demonstrated that age and sex did not significantly impact overall survival ( $p=0.177$ and $p=0.967$, respectively) (Table 4). However, high Kindlin-2 expression was correlated with a worse prognosis $(p<0.001)$ (Figure 1B). Univariate and multivariate Cox proportional survival analyses were performed to analyze the possible interactive effects between clinicopathological variables and Kindlin-2 status on glioma patient prognosis. We determined that pathological grade and Kindlin-2 status were independent risk factors (hazard ratio $[\mathrm{HR}]=1.764,95 \%$ confidence interval $[\mathrm{CI}]=1.076-2.892, p=0.024 ; \mathrm{HR}=1.496,95 \%$ $\mathrm{CI}=1.109-2.0219, p=0.008$, respectively) (Table 5).

\section{Kindlin-2 promotes glioma cell migration, invasion, and proliferation in vitro and in vivo}

We first investigated the expression of endogenous Kindlin-2 in H4, Hs 683, U-87 MG, M059K, and M059J glioma cells by western blotting. All glioma cell lines expressed Kindlin-2. However, M059K cells displayed the highest Kindlin-2 expression (Figure 2A). Therefore, the H4, Hs 683, U-87 MG, and M059J cell lines were optimal for experiments involving ectopic expression of Kindlin-2 through transient transfection of the cells with either Flag-tagged-Kindlin-2 (Flag-Kindlin-2) or an empty vector control. The M059K cells were suitable for experiments in which Kindlin-2 was depleted by siRNA.

We next examined the effects of Kindlin-2 on glioma cell migration and invasion using transwell assays. Kindlin-2 overexpression in H4, Hs 683, U-87 MG, and M059J cells increased migration and invasion compared to empty vector. Knockdown of endogenous Kindlin-2 by siRNA attenuated migration and invasion compared to control siRNA in M059K cells. Overexpression of Kindlin-2 in H4, Hs 683, U-87 $\mathrm{MG}$, and M059J glioma cells enhanced the proliferative capacity. Conversely, siRNA-mediated knockdown of Kindlin-2 in M059K cells decreased the proliferative capacity (Figure 2B-2F).

To analyze the function of Kindlin-2 in vivo, we established U-87 MG cells that stably expressed FlagKindlin-2 or a control lentiviral vector. Mice were subcutaneously injected with either Flag- or FlagKindlin-2-expressing U-87 MG cells and nursed for 30 days. Forced expression of Kindlin-2 enhanced tumor formation and tumor volume compared to control cells $(p=0.037)$ (Figure 3A). We next analyzed the effects of Kindlin-2 on invasion using in vivo metastasis assays. U-87 MG cells that stably expressed Flag-Kindlin-2 or a control lentiviral vector were injected into mice via the tail vein. After 8 weeks, a higher number of microscopic tumor nodules were detected in the lungs of mice in the Flag-Kindlin-2 group compared to the Flag group $(p=0.035)$ (Figure 3B). 


\section{Kindlin-2 activates EGFR signaling and binds to the $E G F R$ promoter to enhance transcription}

EGFR is frequently activated in glioma [23]. Additionally, Kindlin-2 can stabilize EGFR in breast cancer [17]. Therefore, we hypothesized that Kindlin-2 could regulate EGFR signaling in glioma. Immunohistochemical analysis revealed higher EGFR expression in subcutaneous xenografts of mice in the Flag-Kindlin-2 compared to the control group ( $p=0.001$, $r=0.816$, Supplementary Figure S1). We next transiently transfected Flag-Kindlin-2 or control plasmids into U-87 MG cells. In parallel, siRNA targeting Kindlin-2 was transfected into M059K cells. The transfection efficiency was confirmed by western blotting. Overexpression of Kindlin-2 enhanced EGFR expression in U-87 MG cells. Conversely, knockdown of Kindlin-2 by siRNA reduced EGFR protein levels in M059K cells (Figure 4A). To determine whether Kindlin-2 activated signaling downstream of EGFR, we evaluated the activation state of four EGFR-mediated signaling pathways. Up-regulation of Kindlin-2 promoted AKT, ERK, PLC- $\gamma$, and STAT3 phosphorylation but did not alter the total protein levels. In contrast, Kindlin-2 knockdown by siRNA decreased AKT, ERK, PLC- $\gamma$, and STAT3 phosphorylation compared to controls, but had no effect on total protein expression (Figure 4A).
Both transcriptional activation and posttranscriptional modifications can increase EGFR expression. [24] Therefore, we analyzed EGFR mRNA levels by real-time PCR. Overexpression of Kindlin-2 in U-87 MG cells resulted in an increase in the levels of EGFR mRNA. In contrast, depletion of Kindlin-2 by siRNA in M059K cells reduced EGFR mRNA levels (Figure 4B). These data indicated that Kindlin-2 regulated EGFR transcription in glioma cells. To confirm these findings, a reporter plasmid containing the first $2 \mathrm{~kb}$ of the EGFR promoter was constructed for luciferase reporter assays. Overexpression of Kindlin-2 increased EGFR luciferase activity compared to control U-87 MG cells (Figure 4C).

To determine whether Kindlin-2 could bind to the EGFR promoter, we designed four primers within the first $2 \mathrm{~kb}$ of the start site of EGFR for chromatin immunoprecipitation (ChIP) assays using U-87 MG cells. The first primer was positioned downstream of the EGFR start site while primers 2-4 were upstream [25]. The Kindlin-2 antibody effectively immunoprecipitated DNA amplified by EGFR primers 2-4 compared to the immunoglobulin (IgG) controls, whereas the real-time PCR product amplified by the EGFR 1 primer was not significantly detected compared to the IgG control (Figure 4D). These results indicated that Kindlin-2 bound to the upstream region of the EGFR promoter and regulated transcription.
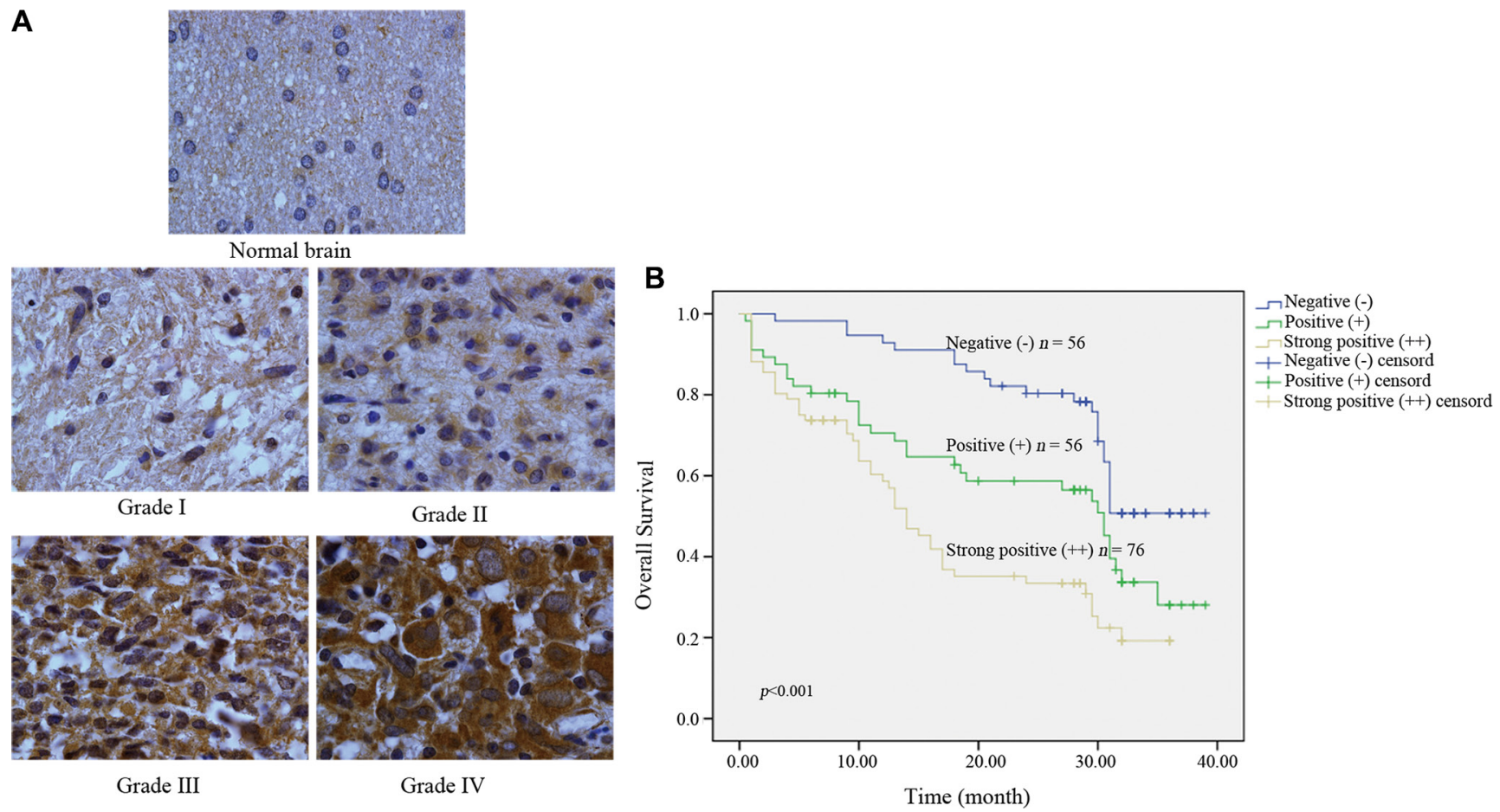

Figure 1: Kindlin-2 expression in intracranial glioma samples and the effects of Kindlin-2 expression on patient prognosis. (A) Kindlin-2 expression in normal brain compared to glioma tissue $(\times 400)$. (B) Kaplan-Meier curves with univariate analyses (log-rank) for patients with negative Kindlin-2 expression (blue line, $n=56$ ), positive Kindlin-2 expression (green line, $n=56$ ), and strong Kindlin-2 expression (brown line, $n=76$ ). 
Table 1: The correlation between clinicopathological parameters and Kindlin-2 expression in 188 glioma cases

\begin{tabular}{|c|c|c|c|c|c|}
\hline \multirow{2}{*}{ Clinicopathological parameters } & \multirow[b]{2}{*}{ Cases } & \multicolumn{2}{|c|}{ Kindlin-2 expression ${ }^{\mathrm{a}}$} & \multirow[b]{2}{*}{$++^{b}$} & \multirow[b]{2}{*}{$p$} \\
\hline & & - & + & & \\
\hline Age (y) & & & & & 0.060 \\
\hline$\leq$ Mean (39.0) & 98 & 36 & 29 & 33 & \\
\hline$>$ Mean & 90 & 20 & 27 & 43 & \\
\hline Sex & & & & & 0.634 \\
\hline Male & 103 & 28 & 33 & 42 & \\
\hline Female & 85 & 28 & 23 & 34 & \\
\hline Tumor grade & & & & & $<0.001$ \\
\hline I-II & 85 & 48 & 28 & 9 & \\
\hline III-IV & 103 & 8 & 28 & 67 & \\
\hline
\end{tabular}

${ }^{a}$ Data are shown as the number of cases; ${ }^{b}-$, negative expression; + , positive expression; ++ , strong positive expression.

Table 2: The correlation between tumor location and Kindlin-2 expression

\begin{tabular}{|c|c|c|c|c|c|c|c|c|c|c|}
\hline \multirow[b]{2}{*}{ Location } & \multirow[b]{2}{*}{ Cases } & \multicolumn{3}{|c|}{ Kindlin-2 ${ }^{\mathrm{a}}$} & \multirow[b]{2}{*}{$p^{\mathbf{c}}$} & \multicolumn{5}{|c|}{$\mathbf{p}^{\prime d}$} \\
\hline & & - & + & $++^{\mathbf{b}}$ & & $\begin{array}{c}\text { Temporal } \\
\text { lobe }\end{array}$ & $\begin{array}{c}\text { Frontal } \\
\text { lobe }\end{array}$ & $\begin{array}{l}\text { Basal ganglia } \\
\text { and thalamus }\end{array}$ & $\begin{array}{c}\text { Parietal and } \\
\text { occipital lobes }\end{array}$ & Brainstem \\
\hline & & & & & $<0.001$ & & & & & \\
\hline Temporal lobe & 34 & 11 & 8 & 15 & & & 0.696 & 0.004 & 0.302 & 0.056 \\
\hline Frontal lobe & 54 & 21 & 14 & 19 & & & & $<0.001$ & 0.329 & 0.179 \\
\hline $\begin{array}{l}\text { Basal ganglia } \\
\text { and thalamus }\end{array}$ & 45 & 2 & 14 & 29 & & & & & 0.003 & $<0.001$ \\
\hline $\begin{array}{l}\text { Parietal and } \\
\text { occipital lobes }\end{array}$ & 29 & 8 & 12 & 9 & & & & & & 0.122 \\
\hline \multirow[t]{2}{*}{ Brainstem } & 26 & 14 & 8 & 4 & & & & & & \\
\hline & 188 & 56 & 56 & 76 & & & & & & \\
\hline
\end{tabular}

${ }^{\mathrm{a}}$ Data are shown as the number of cases; ${ }^{\mathrm{b}}-$, negative expression; + , positive expression; ++ , strong positive expression; ': $p<0.05$ vs. control; ${ }^{\mathrm{d}}: p^{\prime}<0.005$ vs. control.

Table 3: The effect of Kindlin-2 status on outcome for the entire cohort of patients for whom follow-up data was available

\begin{tabular}{lccccc}
\hline & & \multicolumn{2}{c}{ Kindlin-2 expression $^{\mathbf{a}}$} & & $\boldsymbol{p}$ \\
\cline { 3 - 4 } Prognosis & Cases & $-(\boldsymbol{n}=\mathbf{5 6})$ & $+(\boldsymbol{n}=\mathbf{5 6})$ & $++(\boldsymbol{n}=\mathbf{7 6})$ & \\
\hline Alive & & $33(58.9)$ & $24(42.9)$ & $27(35.5)$ & 0.027 \\
Dead & 104 & $23(41.1)$ & $32(57.1)$ & $49(64.5)$ & $<0.001$ \\
Median follow-up & & 30 & 21.5 & 10.5 & \\
\hline
\end{tabular}

${ }^{a}$ Data are shown as the number of cases $(\%)$. 
Table 4: Kaplan-Meier estimates of the overall survival rate for 188 patients with glioma according to age, sex, Kindlin-2 status, and histological grade during the follow-up period of 0.5-39 months

\begin{tabular}{lcc}
\hline \multicolumn{1}{c}{ Variable } & Survival rate (\%) ${ }^{\text {a }}$ & Log-rank test \\
\hline Age $(\mathrm{y})$ & $44(44.9)$ & 0.177 \\
$\leq 39.0(n=98)$ & $40(44.4)$ & \\
$>39(n=90)$ & & 0.967 \\
Sex & $49(47.6)$ & \\
Male $(n=103)$ & $35(41.2)$ & $<0.001$ \\
Female $(n=85)$ & & \\
Pathological grade & $47(55.3)$ & \\
I-II $(n=85)$ & $37(35.9)$ & \\
III-IV $(n=103)$ & & \\
Kindlin-2 status & $33(58.9)$ & \\
$-(n=56)$ & $24(42.9)$ & \\
$+(n=56)$ & $27(35.5)$ & \\
$++(n=76)$ &
\end{tabular}

${ }^{a}$ Data are shown as the number of cases (\%).

Table 5: Univariate and multivariate analyses using Cox proportional hazards models

\begin{tabular}{lcccc}
\hline \multirow{2}{*}{ Variable } & \multicolumn{2}{c}{ Univariate analysis } & \multicolumn{2}{c}{ Multivariate analysis } \\
\cline { 2 - 5 } & HR (95\% CI) & $\boldsymbol{p}$ & HR (95\% CI) & $\boldsymbol{p}$ \\
\hline Age $(\leq 39.0$ vs. $>39.0)$ & $1.298(0.882-1.912)$ & 0.186 & - & - \\
Sex (male vs. female) & $1.008(0.686-1.482)$ & 0.968 & - & - \\
Tumor location & $1.053(0.936-1.185)$ & 0.388 & - & 0.024 \\
Pathological grade (I-II vs. III-IV) & $2.598(1.733-3.894)$ & $<0.001$ & $1.764(1.076-2.892)$ & 0.008 \\
Kindlin-2 status (negative vs. positive) & $1.828(1.430-2.336)$ & $<0.001$ & $1.496(1.109-2.019)$ & 0 \\
\hline
\end{tabular}

We transiently transfected U-87 MG cells with the Flag-Kindlin-2 plasmid along with an anti-EGFR siRNA to determine whether the Kindlin-2-induced effects were dependent on the level of EGFR mRNA. The level of EGFR mRNA was significantly reduced in EGFR knockdown cells even in the presence of the siRNA (Figure 4E, a). Kindlin-2-mediated glioma cell proliferation, migration, and invasion were abolished upon EGFR depletion by siRNA (Figure 4E, b). These results suggested that $E G F R$ transcriptional activity was required for Kindlin-2 function.

\section{Kindlin-2 regulates $E G F R$ transcription through interaction with YB-1 and $\beta$-catenin}

YB-1 is a transcription factor that binds to the $E G F R$ promoter in breast cancer cells [26-27]. Kindlin-2 can form a tripartite transcriptional complex with $\beta$-catenin and T-cell factor 4 (TCF4) to enhance Wnt signaling through expression of Wnt target genes such as Axin2, Cyclin D1, LEF1, Twist, and MMP2 [28]. Therefore, we hypothesized that Kindlin-2 could regulated EGFR transcription in glioma cells through its interaction with $\beta$-catenin and YB-1. 
Using confocal microscopy, we determined that endogenous Kindlin-2, YB-1, and $\beta$-catenin predominantly co-localized in the cytoplasm of U-87 MG cells, although nuclear localization was also observed (Figure 5A). We next immunoprecipitated Kindlin-2 from U-87 MG cell lysates using an anti-Kindlin-2 antibody. Both YB-1 and $\beta$-catenin were detected in the Kindlin2-immunoprecipitated complexes (Figure 5B). Thus, endogenous Kindlin-2 formed a complex with YB-1 and $\beta$-catenin.

\section{YB-1 and $\beta$-catenin are required for Kindlin-2- mediated EGFR transcription}

We investigated whether Kindlin-2-mediated $E G F R$ transcription was dependent on its association with YB-1 and $\beta$-catenin. U-87 MG cells were transiently transfected with Flag-Kindlin-2 and either anti-YB-1 or$\beta$-catenin siRNA. We confirmed that down-regulation of YB-1 or $\beta$-catenin did not affect Kindlin-2 expression (Figure $6 \mathrm{~A}, \mathrm{a})$. Knockdown of $\mathrm{YB}-1$ or $\beta$-catenin reduced EGFR mRNA levels (Figure 6A). Additionally, depletion of endogenous YB-1 or $\beta$-catenin in U-87 MG cells by siRNA (Figure 6B, a) resulted in a decrease in amplification of the immunoprecipitated DNA by EGFR primers 2-4 compared to the IgG control group in ChIP assays (Figure 6B, b). We co-transfected the EGFR reporter, Flag-Kindlin-2, and anti-YB-1 or $-\beta$-catenin siRNA into U-87 MG cells and found that knockdown of either YB-1 or $\beta$-catenin reduced Kindlin-2-induced
EGFR luciferase activity (Figure 6C). These data indicated that YB-1 and $\beta$-catenin were necessary for Kindlin-2 regulation of $E G F R$ transcription.

Increased nuclear localization of active factors can promote EGFR transcription. Although Kindlin-2 localized to the nucleus, whether Kindlin-2 controlled the nuclear localization of YB-1 and $\beta$-catenin was unclear. U-87 MG cells were transiently transfected with either Flag-Kindlin-2 or empty vector. Ectopic expression of Kindlin-2 in U87-MG cells enhanced YB-1 and $\beta$-catenin expression compared to controls (Figure 6D, a). We next analyzed the expression of Kindlin-2, YB-1, and $\beta$-catenin in nuclear and cytoplasmic extracts by western blotting. Although all three proteins were predominantly detected in the cytoplasm, the data indicated they could also localize to the nucleus. Overexpression of Kindlin-2 increased the levels of nuclear YB-1 and $\beta$-catenin (Figure 6D, b).

To investigate the functional association between Kindlin-2, YB-1, and $\beta$-catenin, U-87 MG cells were co-transfected with either anti-YB-1 or $-\beta$-catenin siRNA and Flag-Kindlin-2. Knockdown of YB-1 or $\beta$-catenin individually abolished Kindlin-2induced glioma cell proliferation, migration, and invasion (Figure 6E-6F). These data were consistent with the results of EGFR knockdown in Kindlin-2overexpressing cells (Figure 4E). Collectively, the results indicated that Kindlin-2 formed a complex with YB-1 and $\beta$-catenin to regulate $E G F R$ transcription and promote glioma progression.
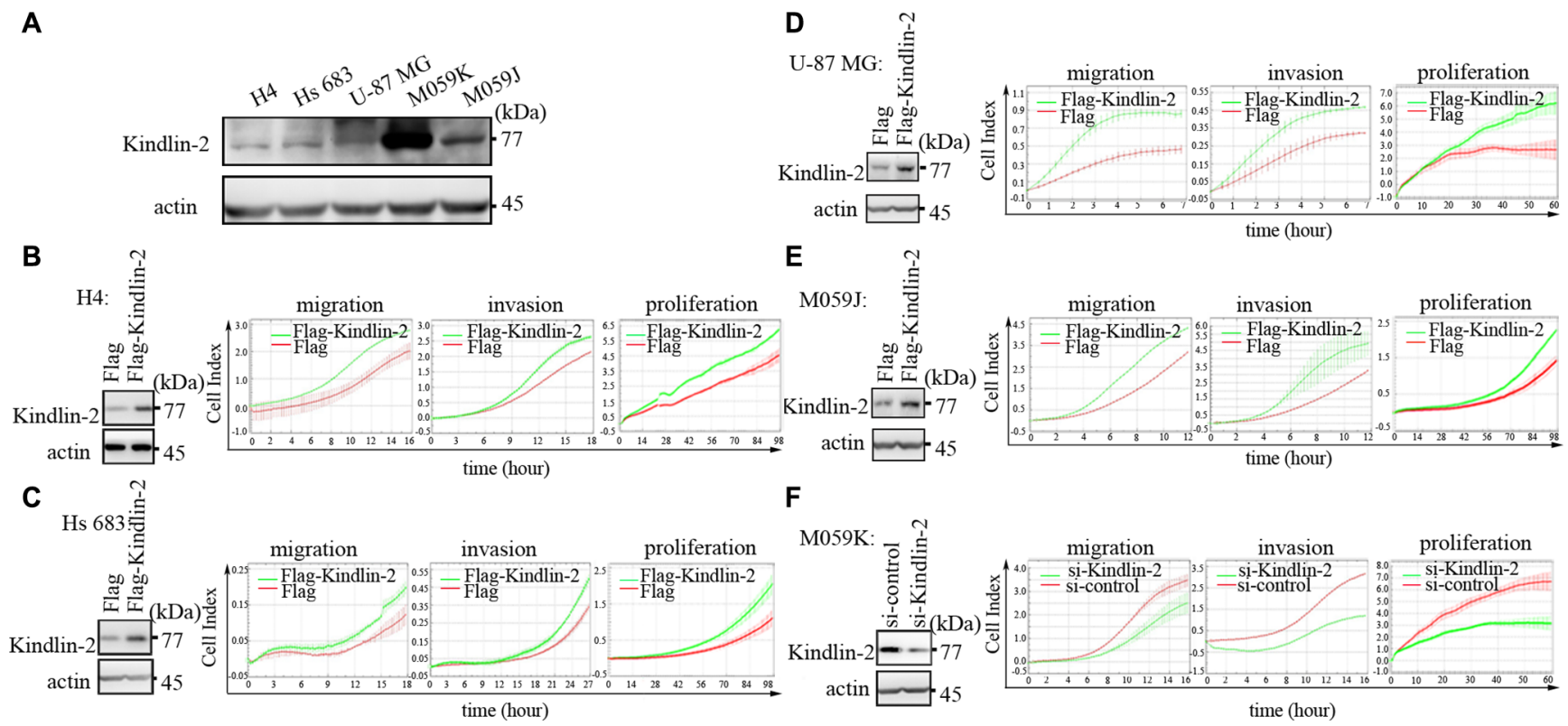

Figure 2: Kindlin-2 promotes glioma cell proliferation, migration, and invasion in vitro. (A) Analysis of Kindlin-2 expression in H4, Hs 683, U-87 MG, M059K, and M059J glioma cell lines by western blotting. (B-E) Ectopic expression of Kindlin-2 in H4, Hs 683, M059J, and U-87 MG cells analyzed by western blotting (left). Overexpression of Kindlin-2 enhances glioma cell proliferation, migration, and invasion (right). (F) Western blot analysis of Kindlin-2 knockdown in M059K cells by siRNA (left). Kindlin-2 knockdown decreases glioma cell proliferation, migration, and invasion (right). Data are presented as the mean $\pm \mathrm{SD}$ from three assays performed in triplicate. 


\section{DISCUSSION}

In this study, we demonstrated that Kindlin-2 expression was positively correlated with clinical tumor grade in human glioma tissue samples. Kindlin-2 status was an independent risk factor, suggesting that Kindlin-2 expression can be an indicator of glioma patient prognosis. We also determined that Kindlin-2 promoted glioma cell motility and proliferation in vitro, and that it could promote growth and invasion in vivo. Finally, Kindlin-2 formed a tripartite transcriptional complex with YB-1 and $\beta$-catenin, which bound to the EGFR promoter and enhanced EGFR transcription and glioma cell proliferation and motility.

Kindlin-2 functions in several signaling pathways to promote tumorigenesis in breast [16-17], non-small cell lung [18], and pancreatic cancer [19]. Opposite functions have been described in mesenchymal tumors, serous epithelial ovarian cancer, and colorectal cancer [21, 29-30]. We found that Kindlin-2 expression was higher in glioma compared to normal brain tissue, and that high Kindlin-2 expression was correlated with high pathological grade. These data indicated that increased Kindlin-2 expression could promote glioma cell proliferation and/or motility. Kaplan-Meier analysis revealed that positive Kindlin-2 expression was associated with poor survival, and that Kindlin-2 was an independent prognostic factor in glioma. Overall, the data suggest that Kindlin-2 expression could be a useful biomarker in glioma.

Although previous studies have indicated that age is a prognostic factor in glioma [31-32], we did not observe an association between age and survival, and kindlin-2 expression in our cohort. This may be explained by the relatively young age of the patients (average age, 39 years). The number of patients should be increased and the age span/distribution noted in future studies. Associations between tumor location and tumor-specific biomarkers have been described previously. For example, high vascular endothelial growth factor (VEGF) was
A a

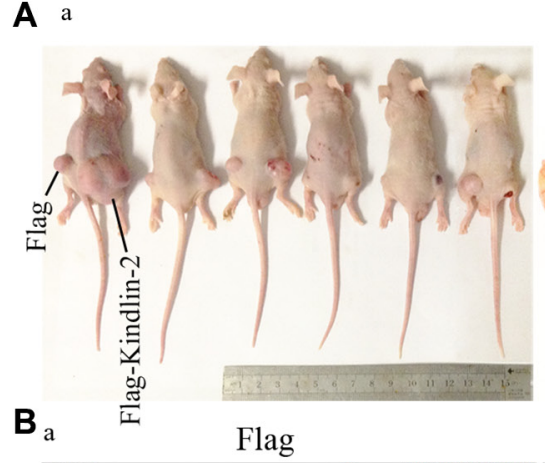

b

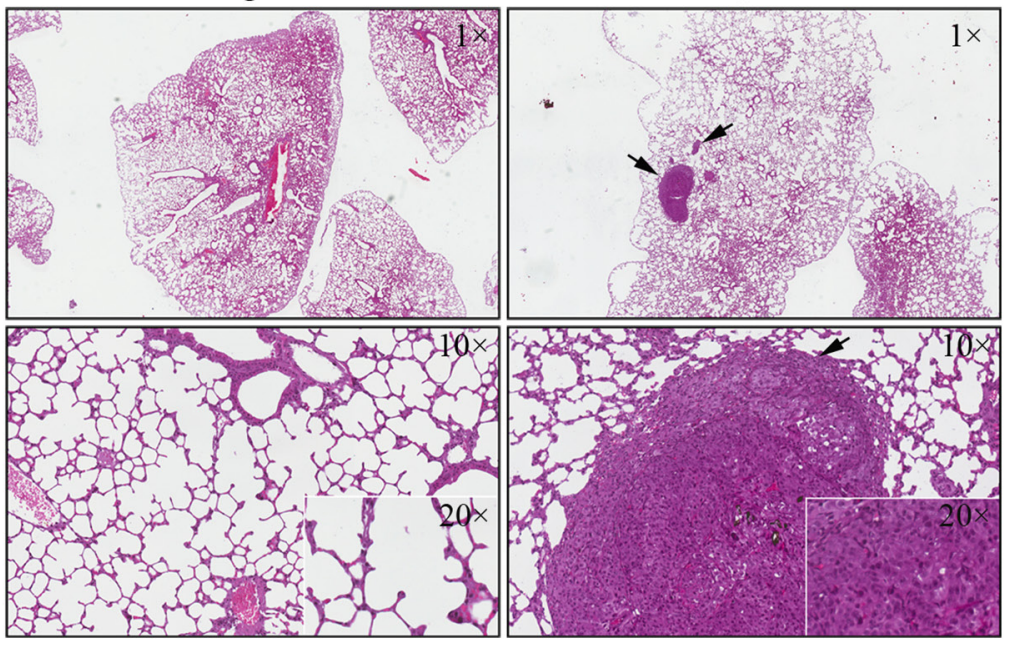

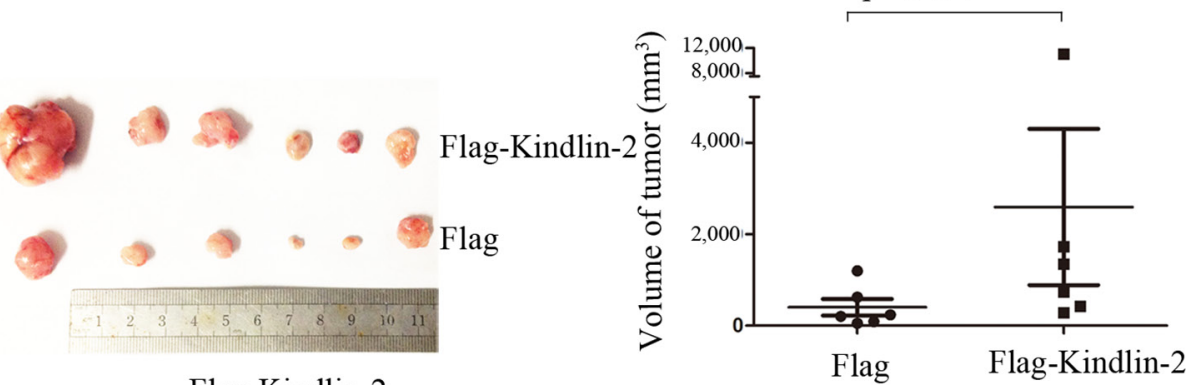

b

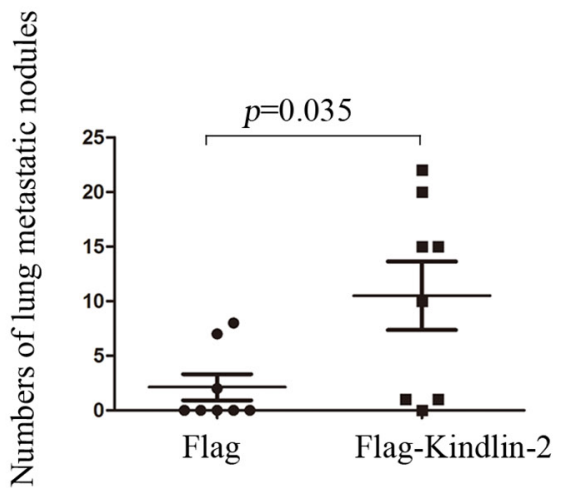

Figure 3: Kindlin-2 promotes glioma cell growth and metastasis in vivo. (A) U-87 MG cells that stably expressed Kindlin-2 or control lentiviral vector were subcutaneously injected into athymic nude mice. The mice were sacrificed by day 30 and tumor formation assessed. (a). Mice were subcutaneously injected with Flag- (left side) or Flag-Kindlin-2-expressing cells (right side) and nursed for 30 days. (b). After 30 days, the tumors were resected and analyzed. (c) Comparison of tumor volume between Kindlin-2 and control mice. The tumor volume was calculated as follows: (major circumference $\times$ minor circumference $\left.{ }^{2}\right) / 2$. (B) Overexpression of Kindlin- 2 promotes glioma metastasis in vivo. (a) Mice were sacrificed and the lungs harvested for H\&E staining 8 weeks after tail vein injection with U-87 MG cells that stably expressed Kindlin- 2 or control lentiviral vector. Representative images were acquired at $1 \times, 10 \times$ and $20 \times$ magnification (the arrows mark metastatic tumor nodules). (b) Quantification of microscopic nodules in the lungs of mice in each group. The error bars represent the SD. ${ }^{*} p<0.05$ was considered significant. 
associated with glioblastoma located in the left frontal lobe and right caudate [33-34]. We determined that glioma tissue samples from the basal ganglia and thalamus had higher Kindlin-2 expression than other regions of the brain. This data suggests that gliomas that arise in the basal ganglia and thalamus may have enhanced growth and motility capacity, which could result in a poor prognosis.

Abnormal cell growth and motility are hallmarks of glioma and other malignant tumors [35]. Interestingly, Kindlin-2 has been shown to promote cell adhesion, motility, and proliferation in several cancers [20-21, 36-37]. We found that ectopic expression of Kindlin-2 promoted glioma cell growth and invasion in vivo. Our data has demonstrated that Kindlin-2 promotes glioma progression through inducing glioma cell motility and proliferation. Kindlin-2 participates in tumorigenesis through multiple mechanisms including EGFR signaling. The major signaling pathways downstream of EGFR include the MEK-ERK, PI3K-AKT, PLC-PKC, and STAT pathways [38]. EGF can stimulate Kindlin-2 expression at both the mRNA and protein levels through the EGFR signaling pathway [17, 39]. The Kindlin-2/ integrin $\beta 1 / \mathrm{AKT}$ axis was shown to contribute to esophageal squamous cell cancer, while the Kindlin-2/
A

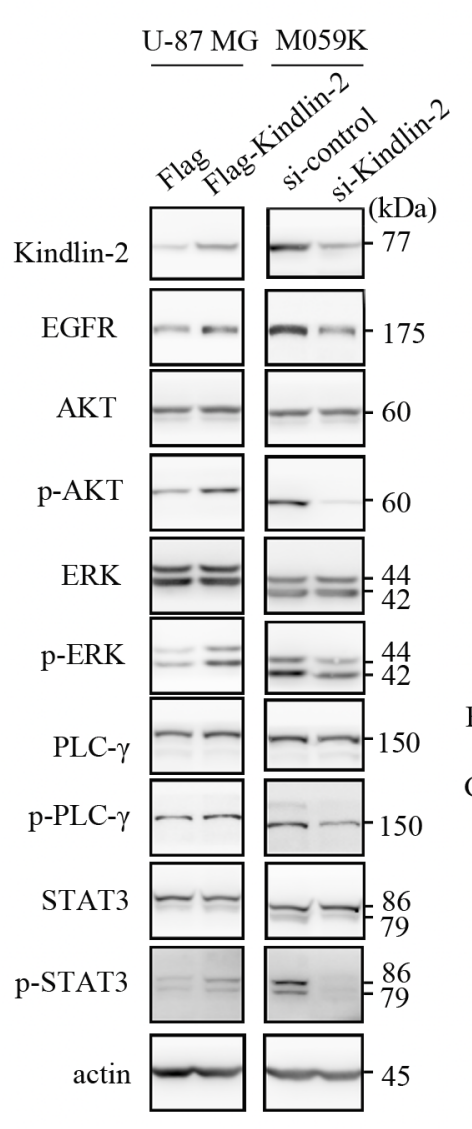

B

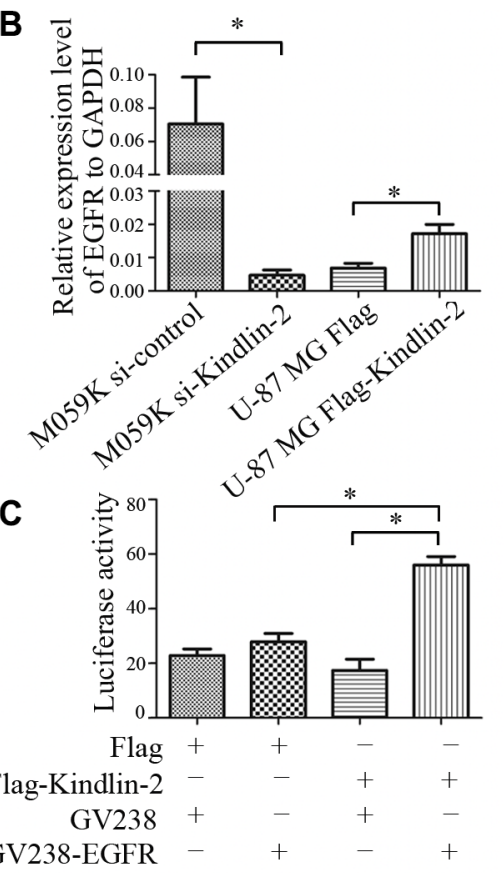

D

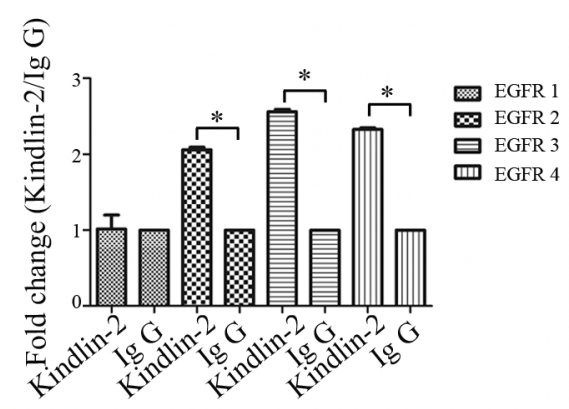

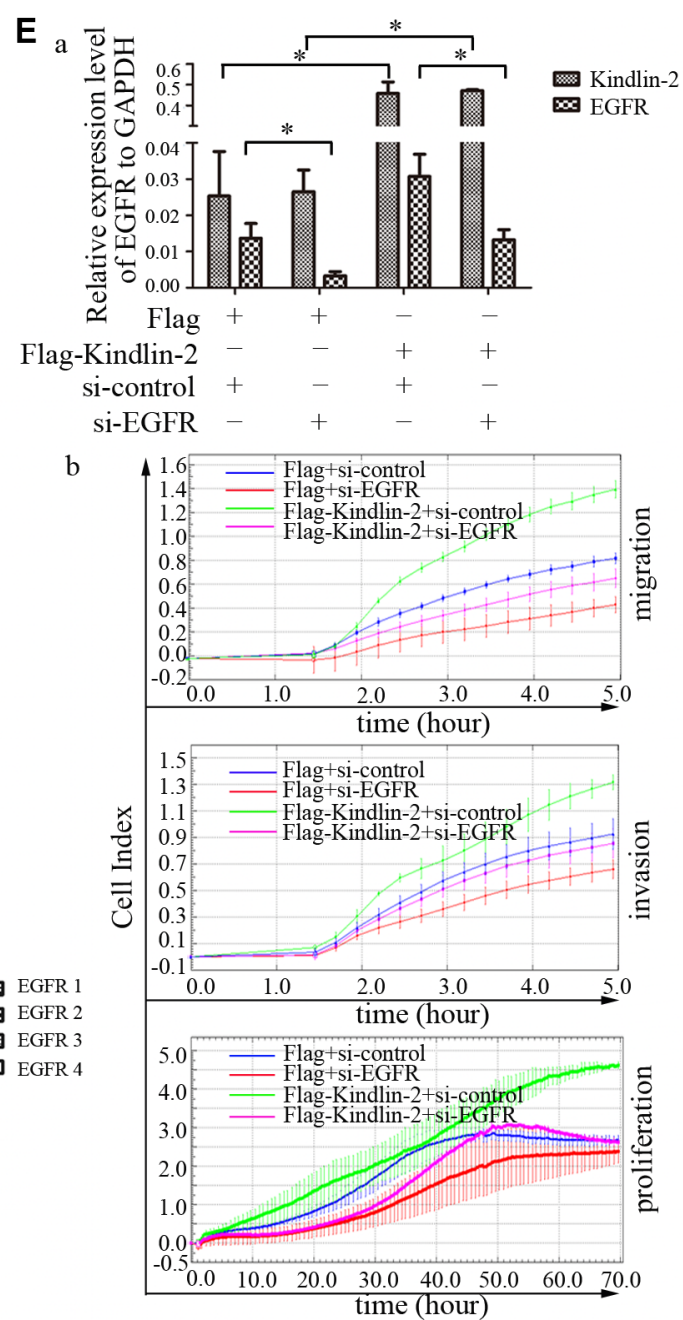

Figure 4: Kindlin-2 activates EGFR signaling and promotes EGFR transcription. (A) Western blot analysis of endogenous EGFR, AKT, ERK, PLC- $\gamma$, and STAT3 levels in U-87 MG cells that overexpressed Kindlin-2 or control vector, and in M059K cells transfected with siRNA against Kindlin-2 or control siRNA. Protein expression was normalized to $\beta$-actin. (B) EGFR mRNA levels in M059K cells measured by real-time PCR after depletion of Kindlin-2 by siRNA, or ectopic expression of Kindlin-2 in U-87 MG cell lines. EGFR mRNA levels were quantified relative to GAPDH. (C) Dual luciferase reporter assays in U-87 MG cells were performed by co-transfecting a reporter plasmid containing the EGFR promoter and an expression plasmid encoding Flag-Kindlin-2 or Flag. Photinus luciferase activity was measured relative to Renilla. (D) ChIP assays to evaluate binding of Kindlin-2 to the EGFR promoter in U-87 MG cells. Four sites in the EGFR promoter (EGFR 1-4) were assessed. (E) Co-transfection of U-87 MG cells with anti-EGFR siRNA and an expression plasmid encoding either Flag-Kindlin-2 or Flag. EGFR and Kindlin-2 mRNA levels were analyzed by real-time PCR (a). Migration, invasion, and proliferation assays (b). Data are shown as the mean \pm SD from three assays performed in triplicate. ${ }^{*} p<0.05$ was considered significant. 
EGFR/AKT axis was shown to be involved in breast cancer [39-40]. In renal tubular epithelial cells (TECs), Kindlin-2 can recruit Sos-1 to regulate Ras activation by activating ERK1/2 and AKT signaling, which promotes TEC epithelial-mesenchymal transition (EMT) [41]. The EGFR signaling pathway also plays a critical role in glioma. EGFR amplification has been observed in $30-50 \%$ of glioblastomas, which is the highest grade glioma [42-43]. These data support the hypothesis that Kindlin-2 is involved in glioma development through regulation of EGFR signaling. Indeed, we found that forced expression of Kindlin-2 in glioma cells increased EGFR expression, while Kindlin-2 depletion decreased EGFR levels in glioma cells.

Several mechanisms are responsible for dysregulation of EGFR expression including genomic alterations and both transcriptional and posttranscriptional modifications [24]. Guo et al. showed that Kindlin-2 altered EGFR protein levels, but not mRNA levels, in breast cancer cells [17]. However, we determined that ectopic expression of Kindlin-2 increased EGFR mRNA levels, which was significantly decreased in Kindlin-2 -depleted glioma cells, suggesting that Kindlin-2 regulated EGFR transcription. Kindlin-2 is an important transcriptional regulator of multiple genes including Axin2, Cyclin D1, LEF1, Twist, MMP2, sFRP1, and Sox9 [11, 28]. Using ChIP and luciferase reporter assays, we demonstrated that Kindlin-2 bound to the upstream region of the $E G F R$ promoter and positively regulated $E G F R$ transcription. The Kindlin-2-induced effects were attenuated by EGFR knockdown, suggesting that EGFR transcription is required for Kindlin-2 function in glioma.

Although the clinical importance of EGFR and many of the proteins that regulate EGFR transcription is clear (e.g. c-Jun, SP-1), the underlying mechanisms have not been fully elucidated [44-45]. Recently, YB-1, an oncogenic transcription/translation factor, was shown to regulate $E G F R$ transcription in breast cancer [25, 27]. YB-1 is overexpressed in many cancers such as breast cancer, lung cancer, and glioma [46-48]. Kindlin-2, which regulates $\mathrm{Wnt}$ signaling, also regulates $\beta$-catenin expression, and forms tripartite transcriptional complex with $\beta$-catenin and TCF4 to promote Wnt target gene expression during breast cancer progression [28]. We hypothesized that the Kindlin-2/ $\beta$-catenin/YB-1 complex could regulate EGFR transcription in glioma. Using confocal microscopy and immunoprecipitation, we demonstrated an interaction between Kindlin-2, YB-1, and $\beta$-catenin in glioma cells. Simultaneous up-regulation of Kindlin- 2 and silencing of YB- 1 or $\beta$-catenin in glioma cells resulted in a decrease in EGFR mRNA levels and transcriptional activity, and disruption of the Kindlin-2 binding sites in the EGFR promoter. Thus, Kindlin-2 forms a tripartite transcriptional complex with YB-1 and $\beta$-catenin to promote $E G F R$ transcription.

We determined that Kindlin-2 enhances YB-1 and $\beta$-catenin protein expression. However, downregulation of YB-1 or $\beta$-catenin did not alter Kindlin-2 expression, suggesting that Kindlin-2 functions upstream of both $\beta$-catenin and YB-1. However, the increase in EGFR transcriptional activity was associated with enhanced nuclear localization of trans-activating elements. Kindlin-2, YB-1, and $\beta$-catenin all exhibited nuclear localization in glioma cells, which confirmed that up-regulation of Kindlin-2 enhanced the nuclear localization of YB-1 and $\beta$-catenin. These results indicated
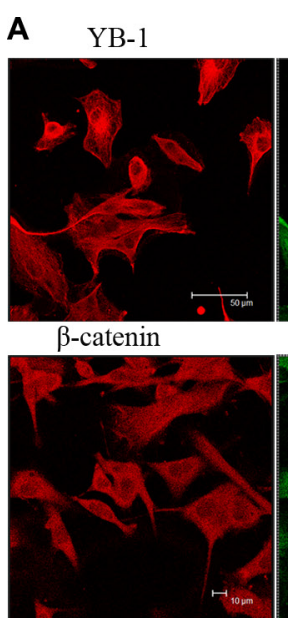

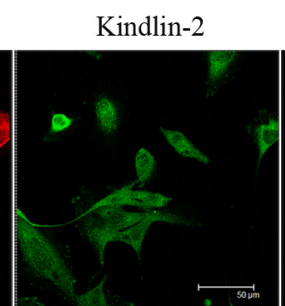

DAPI

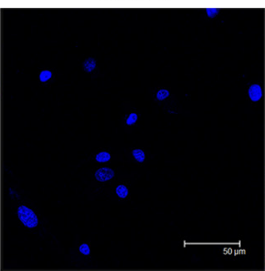

DAPI

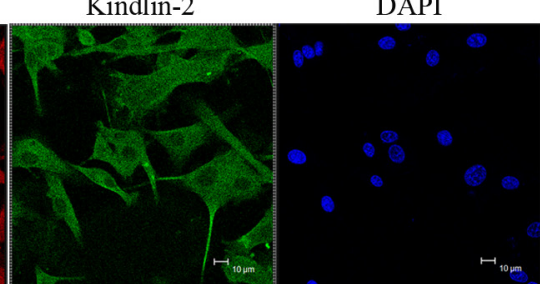

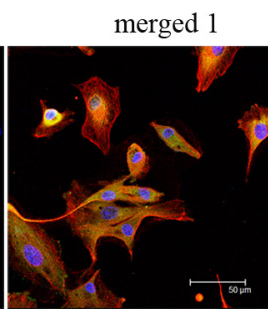

merged 1

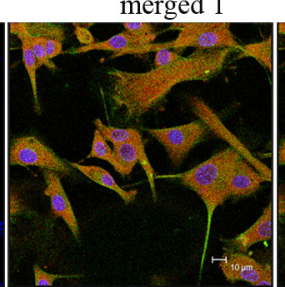

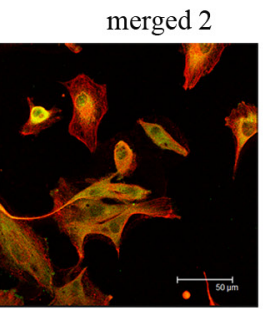

merged 2

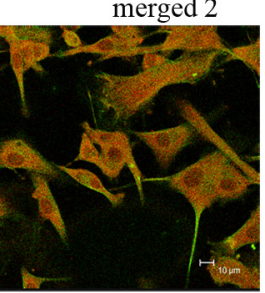

B
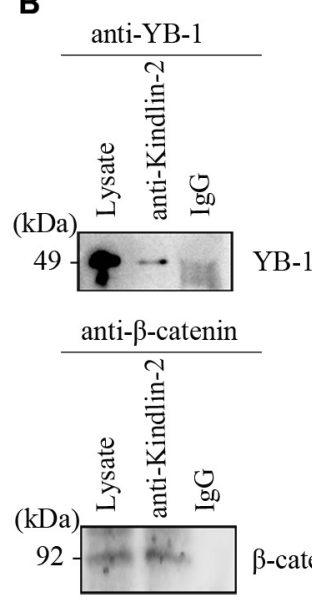

Figure 5: Kindlin-2 forms a complex with YB-1 and $\beta$-catenin. (A) Confocal microscopy indicates Kindlin-2, YB-1, and $\beta$-catenin co-localize in U-87 MG cells. Cells were double stained with an anti-Kindlin-2 monoclonal antibody (green) and an antiYB-1 polyclonal antibody (red), or an anti- $\beta$-catenin polyclonal antibody (red). DNA was stained with DAPI (blue). Kindlin-2, YB-1 (or $\beta$-catenin), and DAPI images were merged in merged image 1. Kindlin-2 and YB-1 (or $\beta$-catenin) were merged in merged image 2 . Yellow dots in merged 1 and merged 2 reflect Kindlin-2 and YB-1 (or $\beta$-catenin) co-localization. Scale bar: $50 \mu \mathrm{m}$ (top) or $10 \mu \mathrm{m}$ (bottom). (B) Immunoprecipitation of Kindlin-2 with YB-1 and $\beta$-catenin. Lysates of human U-87 MG cells were mixed with a mouse anti-Kindlin-2 antibody. The immunoprecipitates were analyzed by western blotting with anti-YB-1 (top) or $\beta$-catenin (bottom) antibodies. 

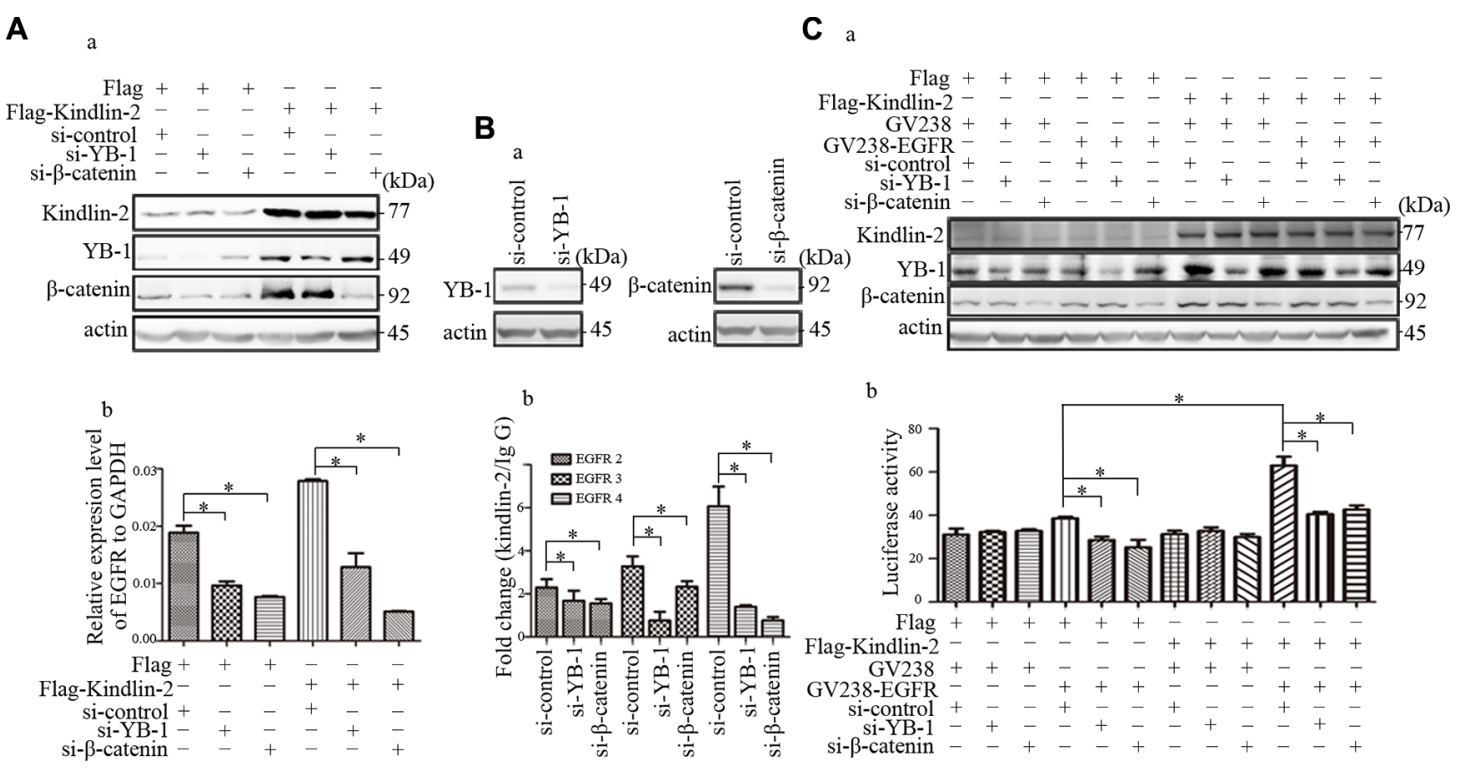

b
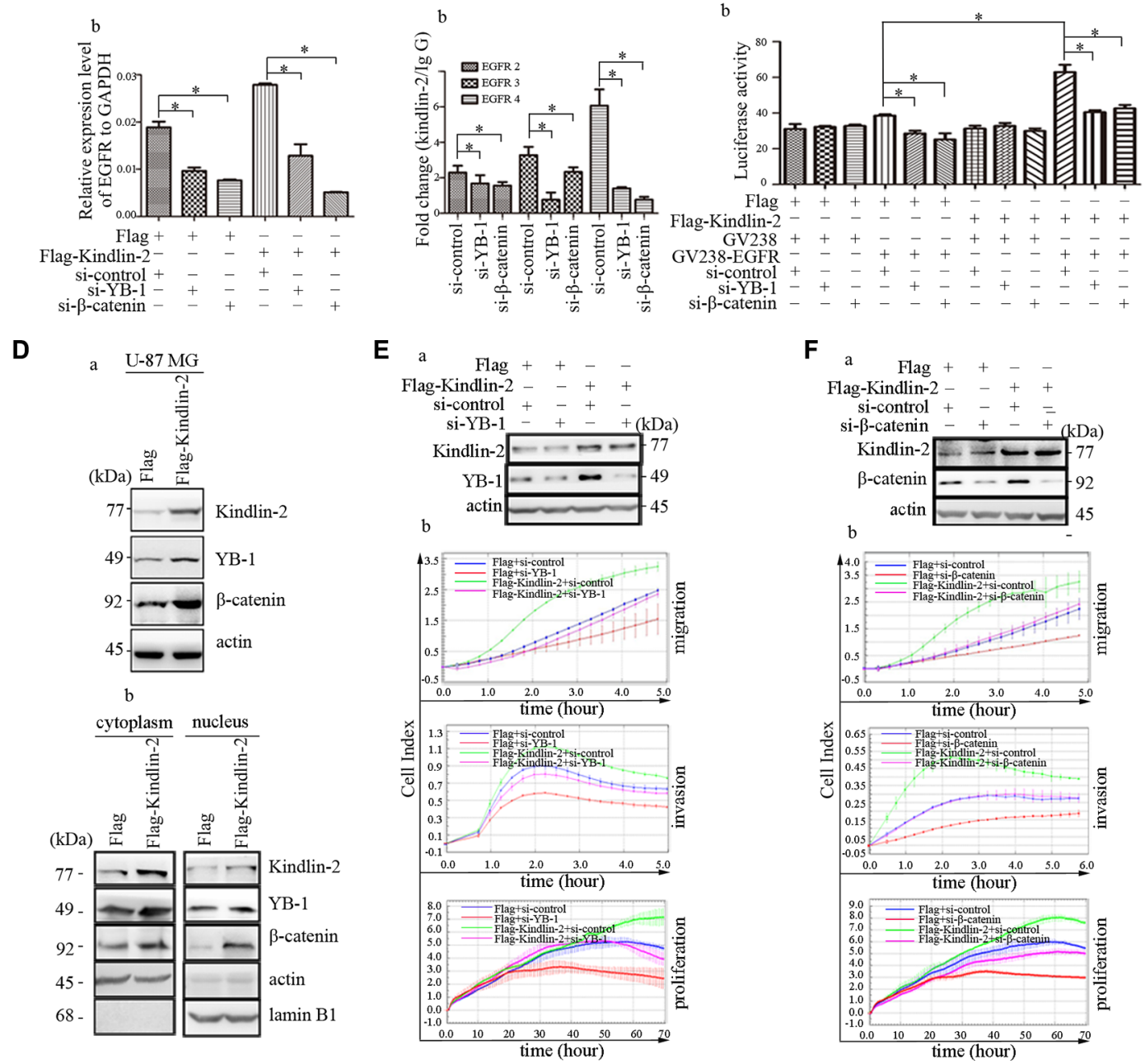

Figure 6: YB-1 and $\beta$-catenin are required for Kindlin-2-mediated EGFR transcription and function in glioma. (A) Analysis of EGFR mRNA levels by real-time PCR after co-transfection of U-87 MG cells with anti-YB-1 siRNA (or anti- $\beta$-catenin siRNA) and an expression plasmid encoding Flag-Kindlin-2 or Flag. Cells were harvested for western blotting to assess the transfection efficiency (a). EGFR mRNA expression was quantified relative to GAPDH (b). (B) YB-1 or $\beta$-catenin were knocked down by siRNA in U-87 MG cells. The cells were then harvested for western blotting to analyzed the transfection efficiency (a). ChIP assays were performed to examine the effects of YB-1 and $\beta$-catenin in the binding regions of Kindlin-2 to the promoter of EGFR 2-4 (b). (C) The reporter plasmid containing the EGFR promoter was co-transfected with an expression plasmid encoding Flag-Kindlin-2 and either anti-YB-1 or anti- $\beta$ catenin siRNA) into U-87 MG cells. The cells were harvested for western blotting to calculate assess the transfection efficiency (a). Dual luciferase reporter assays were then performed. Photinus luciferase activity was measured relative to Renilla (b). (D) Kindlin-2 positively regulates the expression of YB-1 and $\beta$-catenin and promotes their nuclear location. Western blot analysis of Kindlin-2, YB-1, and $\beta$-catenin expression in U-87 MG cells that overexpressed Kindlin-2 or control vector. Protein expression levels were normalized to $\beta$-actin (a). The distributions of Kindlin-2, YB-1, and $\beta$-catenin in the cytoplasm and nucleus were analyzed using a Nuclear and Cytoplasmic Extraction kit after transfection of U-87 NG cells with an expression plasmid encoding either Flag-Kindlin-2 or Flag. Cytoplasmic protein expression was normalized to $\beta$-actin, while nuclear protein expression was normalized to Lamin B1 (b). (E-F) Co-transfection of U-87 MG cells with anti-YB-1 or - $\beta$-catenin siRNA and an expression plasmid encoding either Flag-Kindlin-2 or Flag. Western blots showing the transfection efficiency (a). Analysis of glioma cell migration, invasion, and proliferation (b). Data are presented as the mean \pm SD from three assays performed in triplicate. ${ }^{*} p<0.05$ was considered significant. 
that Kindlin-2 induces YB-1 and $\beta$-catenin expression and nuclear localization to promote $E G F R$ transcription. Kindlin-2 was also shown to promote FoxM1 expression, which could also induce the nuclear localization of $\beta$-catenin in glioma cells $[28,49]$. These data suggest that Kindlin-2 may promote YB-1 and $\beta$-catenin nuclear translocation through FoxM1. Finally, we determined that YB-1 and $\beta$-catenin were required for Kindlin-2-mediated migration, invasion, and proliferation in glioma cells. Therefore, Kindlin-2/YB-1/ $\beta$-catenin/EGFR signaling is critical for glioma development.

In summary, our results indicate that Kindlin-2 is up-regulated in glioma cells and acts as an oncogene. It is an independent risk factor for poor prognosis. The Kindlin-2/YB-1/ $\beta$-catenin complex promotes EGFR transcription and contributes to glioma progression. Kindlin-2 is a potential diagnostic and prognostic marker in glioma, and inhibition of Kindlin-2 may be a novel strategy for glioma treatment.

\section{MATERIALS AND METHODS}

\section{Patient tissue}

A total of 188 glioma specimens were collected from 103 male and 85 female glioma patients (average age of 39.0 years) who underwent treatment for glioma at the Sanbo Brain Hospital at Capital Medical University between 2008 and 2010. Ten normal brains tissue specimens (mostly medulla) were donated by individuals who died in traffic accidents. Patient selection methods and follow-up criteria were described previously [50]. Informed consent was obtained from the patients and the study was approved by the Institutional Research Ethics Committee.

\section{Immunohistochemistry}

Tissue sections were deparaffinized in xylene and rehydrated in graded ethanol. The sections were first incubated with a 1:100 dilution of anti-Kindlin-2 (or anti-EGFR) of primary antibody at $4^{\circ} \mathrm{C}$ overnight, and then incubated with a horse radish peroxidase (HRP)conjugated secondary antibody for $1 \mathrm{~h}$. Sections were stained with 3,3'-diaminobenzidine. The samples were scored as previously described [50].

\section{Subcutaneous and experimental metastasis animal models}

BALB/c nude mice (female, 5 weeks old) were purchased from Beijing Vital River Laboratories (Beijing, China). We subcutaneously injected BALB/c nude mice (on the back sides) with $2 \times 10^{6} \mathrm{U}-87 \mathrm{MG}$ cells that stably expressed Kindlin-2 or the control lentiviral vector (GeneChem, Shanghai, China) and analyzed tumor growth. The mice were sacrificed after $30 \mathrm{~d}$ and tumor volume was estimated: $\mathrm{V}=$ (major circumference $\times$ minor circumference $\left.{ }^{2}\right) / 2$. Cells were injected into mice via the tail vein for metastasis assays. The mice were sacrificed after 8 weeks, and the lungs were enucleated and paraffin embedded. Sections were collected and stained with hematoxylin and eosin (H\&E). Animal experiments were performed according to the Institutional Animal Care and Use Committee guidelines of the Experimental Animal Center of the Cancer Institute and Cancer Hospital of the Chinese Academy of Medical Sciences and Peking Union Medical College.

\section{Cell culture}

Human glioma cell lines (U-87 MG, H4, Hs 683, M059K, and M059J) were purchased from the Cell Culture Center (Chinese Academy of Medical Sciences, Beijing, China). The M059K and M059J cell lines were purchased from the ATCC (Washington, DC, USA). All cell lines were validated by short tandem repeat assays before use. U-87 MG cells were grown in MEM supplemented with $10 \%$ fetal bovine serum (FBS). The H4, Hs 683, M059K, and M059J cells were cultured in DMEM supplemented with $10 \%$ FBS. All cells were cultured at $37^{\circ} \mathrm{C}$ in a $5 \%$ $\mathrm{CO}_{2}$ environment.

\section{Antibodies}

The anti-EGFR, -Akt, -pAkt, -STAT3, -pSTAT3, -Erk1/2, -pErk1/2, -PLC- $\gamma 1$, -pPLC- $\gamma 1$, -YB-1, - $\beta$-catenin, -Lamin B1, and $-\beta$-actin antibodies were purchased from Cell Signaling Technology, Inc. (Danvers, MA, USA). The anti-Migfilin antibody was a gift from Dr. Cary Wu (University of Pittsburgh, Pittsburgh, PA, USA). The HRP-conjugated anti-rabbit and anti-mouse antibodies, Rhodamine (TRITC)-conjugated Affinipure goat antirabbit IgG antibody, Alexa Fluor 488-conjugated Affinipure goat anti-mouse $\mathrm{IgG}$ antibody, and 4',6'-diamidino-2-phenylindole (DAPI) were purchased from Sigma (St. Louis, MO, USA).

\section{Plasmid and siRNA transfection}

The Kindlin-2 plasmid was a gift from Dr. Cary $\mathrm{Wu}$. The siRNAs targeting Kindlin-2, EGFR, YB-1, and $\beta$-catenin were custom designed and purchased from Ribobio (Guangzhou, China). Cells were transfected with either the plasmids or siRNAs using Lipofectamine 2000 (Invitrogen, Carlsbad, CA, USA) using the manufacturer's protocols.

\section{Real-time PCR}

Real-time PCR was performed using the Premix Ex Taq kit (Takara) and a 7300 Real-Time PCR System (Life Technologies) according to the manufacturer's instructions. The primers were the following: used were as follows: 
Kindlin-2: Forward, 5'-CGAGAATCTTGGAGGCCCAT -3', Reverse, 5'-TATTTGGGGGTAGGGGGAGG-3';

EGFR: Forward, 5'-GGTGACCGTTTGGGAGTTGA-3', Reverse, 5'-CCCTGAATGACAAGGTAGCG-3';

GAPDH: Forward, 5'-TGTTGCCATCAATGACCCCTT-3', Reverse, 5'-CTCCACGACGTACTCAGCG-3'.

\section{Western blotting and immunoprecipitation}

Western blotting and immunoprecipitation analyses were performed as described [50]. For immunoprecipitation, lysates were incubated with the primary antibody followed by protein A-agarose beads (Invitrogen). The immune complexes were washed and resuspended in sample buffer for western blotting.

\section{Proliferation, migration, and invasion assays}

Cancer cell proliferation, migration, and invasion were monitored with a xCELLigence Real-Time Cell Analyzer (RTCA)-MP/SP (Acea Biosciences/Roche Applied Science) according to the manufacturer's instructions. We resuspended 2,000-3,000 cells in $100 \mu \mathrm{L}$ of culture medium for proliferation assays and 4-10 $\times 10^{4}$ cells in $100 \mu \mathrm{L}$ of serum-free medium for migration and invasion assays.

\section{Luciferase reporter assays}

U-87 MG cells were co-transfected with a reporter plasmid (GV238 vector) containing the EGFR promoter (GeneChem, Shanghai, China) and an expression plasmid encoding Flag-Kindlin-2 using Lipofectamine 2000 (Invitrogen). We co-transfected the cells with pRLCMV Renilla (Promega) to standardize the transfection efficiency. Luciferase activity was measured using the Dual-Luciferase reporter assay (Promega) and the manufacturer's protocol. Photinus luciferase activity was measured relative to Renilla.

\section{ChIP assays}

ChIP assays were peformed using a ChIP assay kit (Roche, Switzerland) according to the manufacturer's instructions. The EGFR promoter, which spanned regions within the first $2 \mathrm{~kb}$ of the start site, was amplified using the following primers [25].

EGFR-1: Forward, 5'-TCGCCGCCAACGCCA CAAC-3', Reverse, 5'-ACACGCCCTTACCTTTCT TTTCCTCCAG-3'; EGFR-2: Forward, 5'-CCGCGAGTTTCCC TCGCATTTCT-3', Reverse, 5'-CCTTCCCCCTTTCCCTTCTTTTGTTTTAC-3'; EGFR-3: Forward, 5'-TCCCATTTGCCTTTCTCTAGTTT TGTTTTC-3',

Reverse, 5'-GTCCACCCCATCCCCACTGTTCCTTCTC-3'; EGFR-4: Forward, 5'-TTCAGCAAACCCATTCTTCT-3', Reverse, 5'-GCTTCCTGCACACCTGGGCTGAG-3'

\section{Confocal microscopy}

Cells were grown on coverslips for $24 \mathrm{~h}$ and then fixed in cold methanol for $15 \mathrm{~min}$. The cells were incubated with the primary antibodies (diluted 1:100) overnight at $4^{\circ} \mathrm{C}$, and then stained with the second antibodies and DAPI. Immunofluorescence was analyzed using a confocal laser scanning microscope (Leica, Germany).

\section{Statistical analysis}

Statistical analyses were performed with the SPSS 11.5 software. Correlations between the degree of staining and the subgroups according to clinicopathological classifications were calculated using the Pearson's $\chi^{2}$ test. The Kaplan-Meier method was used to estimate the overall survival rate as a function of time. Survival differences were analyzed using log-rank tests. Cox proportional hazards models were used for univariate and multivariate analyses of prognostic factors. Data are shown as the mean \pm standard deviation (SD) and were analyzed using two-sided student's $t$ tests. $P$ values $<0.05$ were considered significant.

\section{CONFLICTS OF INTEREST}

The authors declare that there are no conflicts of interest.

\section{GRANT SUPPORT}

This work was supported by the National 973 Program (2015CB553904), National Natural Science Foundation of China $(81230047,8132109,81502150$, and 81472661), Young Foundation of Beijing Tiantan Hospital of Capital Medical University (2014-YQN-YS-02), Beijing Outstanding Talent Training Project (2015000021469G222), National Basic Research Program of China (No. 2012CB967003), and National Key Technology Research and Development Program of the Ministry of Science and Technology of China (2014BAI04B01, 2015BAI12B04 and 2013BAI09B03). CW was supported by NIH grants (AR064874 and AR068950).

\section{REFERENCES}

1. Bondy ML, Scheurer ME, Malmer B, Barnholtz-Sloan JS, Davis FG, Il'yasova D, Kruchko C, McCarthy BJ, Rajaraman P, Schwartzbaum JA, Sadetzki S, Schlehofer B, Tihan T, et al. Brain tumor epidemiology: consensus from the Brain Tumor Epidemiology Consortium. Cancer. 2008; 113:1953-1968.

2. Wilson TA, Karajannis MA, Harter DH. Glioblastoma multiforme: State of the art and future therapeutics. Surg Neurol Int. 2014; 5:64. 
3. Stupp R, Dietrich PY, Ostermann Kraljevic S, Pica A, Maillard I, Maeder P, Meuli R, Janzer R, Pizzolato G, Miralbell R, Porchet F, Regli L, de Tribolet N, et al. Promising survival for patients with newly diagnosed glioblastoma multiforme treated with concomitant radiation plus temozolomide followed by adjuvant temozolomide. J Clin Oncol. 2002; 20:1375-1382.

4. Amirian E, Liu Y, Scheurer ME, El-Zein R, Gilbert MR, Bondy ML. Genetic variants in inflammation pathway genes and asthma in glioma susceptibility. Neuro Oncol. 2010; 12:444-452.

5. Bao ZS, Chen HM, Yang MY, Zhang CB, Yu K, Ye WL, Hu BQ, Yan W, Zhang W, Akers J, Ramakrishnan V, Li J, Carter B, et al. RNA-seq of 272 gliomas revealed a novel, recurrent PTPRZ1-MET fusion transcript in secondary glioblastomas. Genome Res. 2014; 24:1765-1773.

6. Li B, Huang MZ, Wang XQ, Tao BB, Zhong J, Wang XH, Zhang WC, Li ST. TMEM140 is associated with the prognosis of glioma by promoting cell viability and invasion. J Hematol Oncol. 2015; 8:89.

7. Zhang L, Chen LH, Wan H, Yang R, Wang Z, Feng J, Yang S, Jones S, Wang S, Zhou W, Zhu H, Killela PJ, Zhang J, et al. Exome sequencing identifies somatic gainof-function PPM1D mutations in brainstem gliomas. Nat Genet. 2014; 46:726-730.

8. Ottenhausen M, Krieg SM, Meyer B, Ringel F. Functional preoperative and intraoperative mapping and monitoring: increasing safety and efficacy in glioma surgery. Neurosurg Focus. 2015; 38:E3.

9. Oermann E, Collins BT, Erickson KT, Yu X, Lei S, Suy S, Hanscom HN, Kim J, Park HU, Eldabh A, Kalhorn C, McGrail K, Subramaniam D, et al. CyberKnife enhanced conventionally fractionated chemoradiation for high grade glioma in close proximity to critical structures. J Hematol Oncol. 2010; 3:22.

10. Montanez E, Ussar S, Schifferer M, Bosl M, Zent R, Moser M, Fassler R. Kindlin-2 controls bidirectional signaling of integrins. Genes Dev. 2008; 22:1325-1330.

11. Wu C, Jiao H, Lai Y, Zheng W, Chen K, Qu H, Deng W, Song P, Zhu K, Cao H, Galson DL, Fan J, Im HJ, et al. Kindlin-2 controls TGF-beta signalling and Sox 9 expression to regulate chondrogenesis. Nat Commun. 2015; 6:7531.

12. Qi L, Yu Y, Chi X, Xu W, Lu D, Song Y, Zhang Y, Zhang H. Kindlin-2 interacts with alpha-actinin-2 and beta1 integrin to maintain the integrity of the Z-disc in cardiac muscles. FEBS Lett. 2015; 589:2155-2162.

13. Dowling JJ, Vreede AP, Kim S, Golden J, Feldman EL. Kindlin-2 is required for myocyte elongation and is essential for myogenesis. BMC Cell Biol. 2008; 9:36.

14. Dowling JJ, Gibbs E, Russell M, Goldman D, Minarcik J, Golden JA, Feldman EL. Kindlin-2 is an essential component of intercalated discs and is required for vertebrate cardiac structure and function. Circ Res. 2008; 102:423-431.
15. Ge YS, Liu D, Jia WD, Li JS, Ma JL, Yu JH, Xu GL. Kindlin-2: a novel prognostic biomarker for patients with hepatocellular carcinoma. Pathol Res Pract. 2015; 211:198-202.

16. Zhao T, Guan L, Yu Y, Pei X, Zhan J, Han L, Tang Y, Li F, Fang W, Zhang H. Kindlin-2 promotes genome instability in breast cancer cells. Cancer Lett. 2013; 330:208-216.

17. Guo B, Gao J, Zhan J, Zhang H. Kindlin-2 interacts with and stabilizes EGFR and is required for EGF-induced breast cancer cell migration. Cancer Lett. 2015; 361:271-281.

18. Zhan J, Zhu X, Guo Y, Wang Y, Qiang G, Niu M, Hu J, Du J, Li Z, Cui J, Ma B, Fang W, Zhang H. Opposite role of Kindlin-1 and Kindlin-2 in lung cancers. PLoS One. 2012; 7:e50313.

19. Mahawithitwong $\mathrm{P}$, Ohuchida K, Ikenaga N, Fujita H, Zhao M, Kozono S, Shindo K, Ohtsuka T, Mizumoto K, Tanaka M. Kindlin-2 expression in peritumoral stroma is associated with poor prognosis in pancreatic ductal adenocarcinoma. Pancreas. 2013; 42:663-669.

20. Shen Z, Ye Y, Kauttu T, Seppanen H, Vainionpaa S, Wang S, Mustonen H, Puolakkainen P. The novel focal adhesion gene kindlin-2 promotes the invasion of gastric cancer cells mediated by tumor-associated macrophages. Oncol Rep. 2013; 29:791-797.

21. Ren Y, Jin H, Xue Z, Xu Q, Wang S, Zhao G, Huang J, Huang H. Kindlin-2 inhibited the growth and migration of colorectal cancer cells. Tumour Biol. 2015; 36:4107-4114.

22. Ou YW, Zhao ZT, Wu CY, Xu BN, Song YM, Zhan QM. Mig-2 attenuates cisplatin-induced apoptosis of human glioma cells in vitro through AKT/JNK, AKT/p38 signaling pathways. Acta Pharmacol Sin. 2014; 35:1199-1206.

23. Huang PH, Xu AM, White FM. Oncogenic EGFR signaling networks in glioma. Sci Signal. 2009; 2:re6.

24. Sebastian S, Settleman J, Reshkin SJ, Azzariti A, Bellizzi A, Paradiso A. The complexity of targeting EGFR signalling in cancer: from expression to turnover. Biochim Biophys Acta. 2006; 1766:120-139.

25. Wu J, Lee C, Yokom D, Jiang H, Cheang MC, Yorida E, Turbin D, Berquin IM, Mertens PR, Iftner T, Gilks CB, Dunn SE. Disruption of the Y-box binding protein-1 results in suppression of the epidermal growth factor receptor and HER-2. Cancer Res. 2006; 66:4872-4879.

26. Nielsen TO, Hsu FD, Jensen K, Cheang M, Karaca G, $\mathrm{Hu} \mathrm{Z}$, Hernandez-Boussard T, Livasy C, Cowan D, Dressler L, Akslen LA, Ragaz J, Gown AM, et al. Immunohistochemical and clinical characterization of the basal-like subtype of invasive breast carcinoma. Clin Cancer Res. 2004; 10:5367-5374.

27. Stratford AL, Habibi G, Astanehe A, Jiang H, Hu K, Park E, Shadeo A, Buys TP, Lam W, Pugh T, Marra M, Nielsen TO, Klinge U, et al. Epidermal growth factor receptor (EGFR) is transcriptionally induced by the Y-box binding protein-1 (YB-1) and can be inhibited with Iressa in basal-like breast cancer, providing a potential target for therapy. Breast Cancer Res. 2007; 9:R61. 
28. Yu Y, Wu J, Wang Y, Zhao T, Ma B, Liu Y, Fang W, Zhu WG, Zhang H. Kindlin 2 forms a transcriptional complex with beta-catenin and TCF4 to enhance Wnt signalling. EMBO Rep. 2012; 13:750-758.

29. Shi X, Wu C. A suppressive role of mitogen inducible gene-2 in mesenchymal cancer cell invasion. Mol Cancer Res. 2008; 6:715-724.

30. Ren C, Du J, Xi C, Yu Y, Hu A, Zhan J, Guo H, Fang W, Liu C, Zhang H. Kindlin-2 inhibits serous epithelial ovarian cancer peritoneal dissemination and predicts patient outcomes. Biochem Biophys Res Commun. 2014; 446:187-194.

31. Chaichana KL, Pendleton C, Chambless L, CamaraQuintana J, Nathan JK, Hassam-Malani L, Li G, Harsh GRt, Thompson RC, Lim M, Quinones-Hinojosa A. Multiinstitutional validation of a preoperative scoring system which predicts survival for patients with glioblastoma. J Clin Neurosci. 2013; 20:1422-1426.

32. Scott JN, Rewcastle NB, Brasher PM, Fulton D, MacKinnon JA, Hamilton M, Cairncross JG, Forsyth P. Which glioblastoma multiforme patient will become a long-term survivor? A population-based study. Ann Neurol. 1999; 46:183-188.

33. Fan X, Wang Y, Wang K, Liu S, Liu Y, Ma J, Li S, Jiang T. Anatomical specificity of vascular endothelial growth factor expression in glioblastomas: a voxel-based mapping analysis. Neuroradiology. 2015.

34. Kappadakunnel M, Eskin A, Dong J, Nelson SF, Mischel PS, Liau LM, Ngheimphu P, Lai A, Cloughesy TF, Goldin J, Pope WB. Stem cell associated gene expression in glioblastoma multiforme: relationship to survival and the subventricular zone. J Neurooncol. 2010; 96:359-367.

35. Wen PY, Kesari S. Malignant gliomas in adults. N Engl J Med. 2008; 359:492-507.

36. An Z, Dobra K, Lock JG, Stromblad S, Hjerpe A, Zhang H. Kindlin-2 is expressed in malignant mesothelioma and is required for tumor cell adhesion and migration. Int J Cancer. 2010; 127:1999-2008.

37. Shen Z, Ye Y, Dong L, Vainionpaa S, Mustonen H, Puolakkainen P, Wang S. Kindlin-2: a novel adhesion protein related to tumor invasion, lymph node metastasis, and patient outcome in gastric cancer. Am J Surg. 2012; 203:222-229.

38. Hsu JM, Chen CT, Chou CK, Kuo HP, Li LY, Lin CY, Lee HJ, Wang YN, Liu M, Liao HW, Shi B, Lai CC, Bedford MT, et al. Crosstalk between Arg 1175 methylation and Tyr 1173 phosphorylation negatively modulates EGFRmediated ERK activation. Nat Cell Biol. 2011; 13:174-181.

39. He Y, Esser P, Schacht V, Bruckner-Tuderman L, Has C. Role of kindlin-2 in fibroblast functions: implications for wound healing. J Invest Dermatol. 2011; 131:245-256.

40. Zhang HF, Alshareef A, Wu C, Li S, Jiao JW, Cao HH, Lai R, Xu LY, Li EM. Loss of miR-200b promotes invasion via activating the Kindlin-2/integrin beta1/AKT pathway in esophageal squamous cell carcinoma: An E-cadherinindependent mechanism. Oncotarget. 2015; 6:28949-28960. doi: 10.18632/oncotarget.5027.

41. Wei X, Wang X, Xia Y, Tang Y, Li F, Fang W, Zhang H. Kindlin-2 regulates renal tubular cell plasticity by activation of Ras and its downstream signaling. Am J Physiol Renal Physiol. 2014; 306:F271-278.

42. Wechsler-Reya R, Scott MP. The developmental biology of brain tumors. Annu Rev Neurosci. 2001; 24:385-428.

43. Aldape KD, Ballman K, Furth A, Buckner JC, Giannini C, Burger PC, Scheithauer BW, Jenkins RB, James CD. Immunohistochemical detection of EGFRvIII in high malignancy grade astrocytomas and evaluation of prognostic significance. J Neuropathol Exp Neurol. 2004; 63:700-707.

44. Zenz R, Scheuch H, Martin P, Frank C, Eferl R, Kenner L, Sibilia M, Wagner EF. c-Jun regulates eyelid closure and skin tumor development through EGFR signaling. Dev Cell. 2003; 4:879-889.

45. Kageyama R, Merlino GT, Pastan I. Epidermal growth factor (EGF) receptor gene transcription. Requirement for Sp1 and an EGF receptor-specific factor. J Biol Chem. 1988; 263:6329-6336.

46. Bargou RC, Jurchott $\mathrm{K}$, Wagener C, Bergmann S, Metzner S, Bommert K, Mapara MY, Winzer KJ, Dietel M, Dorken B, Royer HD. Nuclear localization and increased levels of transcription factor YB-1 in primary human breast cancers are associated with intrinsic MDR1 gene expression. Nat Med. 1997; 3:447-450.

47. Shibahara K, Sugio K, Osaki T, Uchiumi T, Maehara Y, Kohno K, Yasumoto K, Sugimachi K, Kuwano M. Nuclear expression of the Y-box binding protein, YB-1, as a novel marker of disease progression in non-small cell lung cancer. Clin Cancer Res. 2001; 7:3151-3155.

48. Mantwill K, Naumann U, Seznec J, Girbinger V, Lage H, Surowiak P, Beier D, Mittelbronn M, Schlegel J, Holm PS. YB-1 dependent oncolytic adenovirus efficiently inhibits tumor growth of glioma cancer stem like cells. J Transl Med. 2013; 11:216.

49. Zhang N, Wei P, Gong A, Chiu WT, Lee HT, Colman H, Huang H, Xue J, Liu M, Wang Y, Sawaya R, Xie K, Yung WK, et al. FoxM1 promotes beta-catenin nuclear localization and controls Wnt target-gene expression and glioma tumorigenesis. Cancer Cell. 2011; 20:427-442.

50. Ou Y, Ma L, Dong L, Zhao Z, Zhou W, Fan J, Wu C, Yu C, Zhan Q, Song Y. Migfilin Protein Promotes Migration and Invasion in Human Glioma through Epidermal Growth Factor Receptor-mediated Phospholipase C-gamma and STAT3 Protein Signaling Pathways. J Biol Chem. 2012; 287:32394-32405. 